\title{
INFLUENCE OF PRESTRESS LEVEL ON NSM CFRP LAMINATES FOR THE FLEXURAL STRENGTHENING OF RC BEAMS
}

\author{
Mohammadali Rezazadeh ${ }^{1}$, Inês Costa ${ }^{2}$, Joaquim Barros ${ }^{3}$
}

\begin{abstract}
This study presents an experimental program to evaluate the influence of the prestressing technique on the flexural behavior of reinforced-concrete (RC) beams strengthened with near-surface-mounted (NSM) carbonfiber-reinforced-polymer (CFRP) laminates. The experimental program was organized to highlight the benefits of this technique for flexural strengthening of RC beams with low reinforcement ratio, susceptible of not respecting serviceability-limit-state (SLS) conditions, namely the deflection limit. For this purpose, five RC beams were fabricated to be tested under monotonic four-point loading. One beam was kept unstrengthened as a control beam, and another one was strengthened with a non-prestressed NSM CFRP laminate. The remaining beams were reinforced with a NSM CFRP laminate prestressed at $20 \%, 30 \%$ and $40 \%$ of its nominal tensile strength. Based on the results, applying the prestress force provided an increase of load carrying capacity corresponding to the concrete cracking and steel yielding initiations compared to the non-prestressed strengthened beam. Moreover, the influence of prestress level on the prevailing failure mode of the tested beams was assessed, and the relevant results are presented and discussed. An advanced numerical strategy was also developed to simulate the tested beams, which was demonstrated capable of being used for the design of this type of structures.
\end{abstract}

Keywords: NSM technique, CFRP laminate, prestress force, flexural strengthening, numerical modeling.

\footnotetext{
${ }^{1} \mathrm{PhD}$ Student, ISISE, Dept. Civil Engineering, University of Minho, Campus de Azurém, Guimarães, Portugal, M.rezazadeh@civil.uminho.pt, http://www.isise.net.

${ }^{2} \mathrm{PhD}$ Student, ISISE, Dept. Civil Engineering, University of Minho, Campus de Azurém, Guimarães, Portugal, Ines.costa@civil.uminho.pt, http://www.isise.net.

${ }^{3}$ Full Professor, ISISE, Dep. Civil Engineering, University of Minho, Campus de Azurém, Guimarães, Portugal, Barros@civil.uminho.pt, http://www.isise.net.
} 


\section{Introduction}

Fiber reinforced polymer (FRP) systems have been extensively developed as an alternative to steel to strengthen reinforced concrete (RC) structures due to the several advantages associated with these composite materials [1]. These FRP systems are being used for the flexural and shear strengthening of RC structures by using either externally bonded reinforcing (EBR) or near surface mounted (NSM) techniques [2-8]. Studies have shown that the NSM technique, based on the insertion of carbon fiber reinforced polymer (CFRP) laminates into grooves opened on the concrete cover of the RC elements to be strengthened, assures higher shear and flexural strengthening effectiveness than EBR technique. This higher effectiveness of the NSM technique can be attributed to the largest ratio of bond area to cross sectional area of the CFRP laminate, and higher confinement provided by the surrounding concrete to this reinforcement when using this technique [2,9-11]. Combining NSM CFRP reinforcement for the flexural strengthening, with CFRP strips applied according to EBR technique, resulted to enhance the energy dissipation capacity of the strengthened structures due to increase in the concrete confinement [12].

The most common CFRP bar types used in the NSM strengthening technique have cross sections of rectangular, square and circular shape. CFRP bars of rectangular cross section with high width to thickness ratio exhibit better bond behavior than other types of bars due to the higher contact perimeter to cross sectional area ratio $[9,13]$. The NSM strengthening technique with CFRP laminates can significantly increase the load carrying capacity of RC beams, especially when the percentage of existing steel reinforcement is relatively low [10].

In different strengthening situations, the increase of load carrying capacity for deflection levels corresponding to the serviceability limit state (SLS) provided by the NSM technique can be insufficient [10]. However, applying an appropriate prestress level on the CFRP can increase significantly the load carrying capacity of the RC beams for deflection levels corresponding to SLS. By using prestressed CFRP laminates several strengthening advantages can be obtained, like decreasing the width or even closing existing cracks, higher mobilization of the CFRP tensile strength, and higher load carrying capacity at yield initiation of the longitudinal steel bars [14-20]. For uncracked RC elements (not current in structural strengthening), the load carrying capacity at cracking initiation can be increased by applying prestressed CFRP laminates. 
The present work aims to experimentally evaluate the effectiveness of prestressed CFRP laminates applied according to the NSM technique for the flexural strengthening of beams flexurally reinforced with relatively small percentage of longitudinal bars. These RC beams do not respect the deflection limit at SLS imposed by Eurocode [21], which is a recurrent issue in buildings constructed in the 60 's until the 80 's. Moreover, the effectiveness of the prestressing technique on the prevailing failure mode, and the short-term behavior immediately after the release of prestress force were also evaluated. To apply the prestress force to the CFRP laminates, a prestress line was designed and built in the laboratory of Minho University, whose detailed description can be found elsewhere [22].

A reliable simulation of the behavior of $\mathrm{RC}$ beams strengthened with the proposed prestressing technique requires advanced numerical modeling based on the finite element method (FEM), which is still a challenge on the computational mechanical domain. Hence, a 3D nonlinear FE model is developed to simulate the experimental tests by considering the nonlinear behavior of the constitutive materials, the CFRP-adhesive-concrete interfaces, and modeling the prestress process of the CFRP elements adopted in these tests. The numerical model is briefly described, and relevant results are presented.

\section{Experimental Program}

\subsection{Specimens and test setup}

The experimental program reported in this paper was composed of five RC beams. One of the RC beams was kept unstrengthened, while another one was flexurally strengthened with a non-prestressed CFRP laminate applied according to the NSM technique, consisting in a passive strengthened beam. The remaining three beams were flexurally strengthened with NSM CFRP laminate prestressed up to approximately $20 \%, 30 \%$ and $40 \%$ of its nominal tensile strength.

The geometry, support and loading conditions are schematically represented in Figure 1a, and the arrangement of the tensile and compressive longitudinal steel reinforcements of the beams is depicted in Figure $1 \mathrm{~b}$ (dimensions are in $\mathrm{mm})$. To evaluate the tensile strains on the longitudinal steel bars, three strain gauges were installed on the bottom steel bars as represented in Figure 1c (SG 2,3 and 5). One strain gauge was installed on the top fiber of the concrete at mid-section of the beams to monitor the concrete strain (SG 1 in Figure 1c). The shear reinforcement ratio $\left(\rho_{s w}=\right.$ 
$A_{s w} / b_{w} s=0.47 \%$, where $A_{s w}$ is the cross sectional area of a steel stirrup and $b_{w}$ is the width of beam's cross section) and spacing $(s=80 \mathrm{~mm})$ of the steel stirrups were designed to avoid shear failure, following the recommendations of [21]. For the flexural strengthening of the RC beams, a CFRP laminate of $1.4 \times 20 \mathrm{~mm}^{2}$ cross sectional area was installed into a groove of $6 \times 24 \mathrm{~mm}^{2}$ cross section opened on the concrete cover along the total length of the beam (Figure 1b). The tensile strains of the CFRP reinforcement were recorded by installing two strain gauges on the laminate (SG 4 and 6 in Figure 1c), while in the case of the prestressed CFRPs, one more strain gauge was placed at $200 \mathrm{~mm}$ far from the end of the CFRP bonded length (SG7 shown in Figure 1c). This extra SG was applied for a better assessment of the prestress losses. However, in order to simulate, as much as possible, the restrictions found in a real strengthening application in terms of anchorage conditions for the NSM technique (such as the anchorage pieces represented in Figure 3), a length of $150 \mathrm{~mm}$ of the CFRP laminates at each extremity of the beams was not bonded with epoxy adhesive to the concrete (see Figure 1a). These simply supported beams were monotonically loaded up to failure under four-point loading, by imposing a deflection rate of $1.2 \mathrm{~mm} / \mathrm{min}$ controlled by the servo-actuator that applied the load (Figure 1a).

\subsection{Prestressing setup and procedure}

To apply the prestress force to the CFRP laminate, the prestressing system represented in Figure 2 was designed and installed in the laboratory at Minho University [22]. The prestress force was applied at the sliding extremity of the prestressing system using a hollow hydraulic cylinder with maximum capacity of $200 \mathrm{kN}$, to which is connected a through-hole load cell of same capacity to control release rate of the prestress force. To ensure that the release of the prestress force would occur simultaneously in both extremities of the RC beams, two steel rollers were placed under the beams. Additionally, an electrical strain gauge was installed on the CFRP laminate at the fixed extremity (outside the bonded length of the CFRP reinforcement) to monitor the release rate of the prestress force at this extremity and to assess the simultaneity of this release process.

The applied prestress level was controlled by the average strain recorded by three strain gauges installed on the CFRP laminate and considering the material properties supplied by manufacturer (elasticity modulus of $150 \mathrm{GPa}$ and nominal tensile strength of $2000 \mathrm{MPa}$ ). After applying the prestress force, the groove was filled with epoxy adhesive, and this 
force was removed after 72 hours of adhesive-curing at room temperature. To avoid damage in the CFRP-adhesiveconcrete connection, the prestress force was released at a relatively low rate of $0.3 \mathrm{kN} / \mathrm{min}$.

The prestressing system used in laboratory conditions is a simplification of the method proposed by Barros for real conditions on the flexural strengthening with NSM prestressed CFRP laminates [23], which is schematically represented in Figure 3. To apply a certain prestress level on the CFRP laminates using this prestressing system, after removing the concrete cover near the zones where the laminate will be anchored at the extremities of the beams, the prestress force is applied by an actuator through the telescopic steel tubes to the anchorage pieces (Figure 3). The detailed description and the design of this system can be found elsewhere [24]. The prestressing system implemented in the laboratory was designed to take advantage of an existing high stiff reaction frame composed of steel profiles, and aiming a relatively ease, fast and safe application of prestress to the CFRP laminates in laboratory conditions.

\subsection{Material properties}

The average and the standard deviation values of the main properties for the concrete, steel bars, CFRP laminate and epoxy adhesive are indicated in Tables 1 to 4 . In Table $1 f_{c m}$ and $E_{c}$ represent the average values of the compressive strength and young's modulus of concrete, respectively. In Table $2, f_{\text {sym }}, f_{\text {sum }}$ and $E_{s}$ are the average values of the stress at yield initiation, tensile strength and elasticity modulus of steel bars, respectively. Table 3 reports the average values

of the tensile strength, $f_{f u m}$, ultimate tensile strain, $\varepsilon_{f u m}$, and elasticity modulus, $E_{f}$, for the CFRP laminate. Finally, in Table $4, f_{\text {eum }}$ and $E_{e}$ are the average values of the tensile strength and elasticity modulus of the epoxy adhesive, respectively.

\section{Experimental Results}

\subsection{Short-term prestress losses and initial camber}

Due to the eccentricity of the prestress force in relation to the centroidal axis of the beam cross section, a negative bending moment is created after the release of the prestress force, causing a negative camber (upward deflection) in the beam, as well as a loss of strain in the CFRP laminate. In these prestressed RC beams, the short-term prestress 
losses were defined as the losses of strain immediately after removing the totality of the prestress load. These prestress losses and initial camber were determined by monitoring the strain variation in the CFRP laminate and the deflection at mid-span during the release of the prestress force. In fact, a decrease of the tensile strain in the CFRP laminate was observed in consequence of the negative camber caused by the effect of the prestress release. The main relevant results of the prestress losses and initial camber of the prestressed beams are indicated in Table 5. As expected, the prestress losses increased with the prestress level, but the maximum value was limited to approximately $2 \%$.

\subsection{Load-deflection curves}

The force versus mid-span deflection relationships of all tested beams is depicted in Figure 4, where all strengthened beams, regardless the prestressing level, presented an increase of more than $50 \%$ in terms of the ultimate load carrying capacity when compared to the control beam.

As already indicated, a relatively low steel reinforcement ratio $\left(\rho_{s}=A_{s} / b_{w} \cdot d=0.39 \%\right.$, where $A_{s}$ is the cross sectional area of tensile steel reinforcement and $d$ is the effective depth of the beam's cross section) and concrete strength were adopted for the beams of this experimental program in order to evaluate the efficiency of the prestressed NSM CFRP technique on the flexural behavior of RC elements susceptible of developing abnormally high deflections. Assuming these RC beams as representative of constructions built in the 60's to 80's according to the Portuguese (PT) design regulations (also typical of buildings of several European countries), the flexural reinforcement did not yield at SLS, since the deflection limit was $\mathrm{L} / 400=5.5 \mathrm{~mm}$. However, the safety margin between the load at yield initiation and the load at SLS is quite small (6\%). Furthermore, these beams do not accomplish the requirements of the actual European design recommendations [21], since for the deflection limit at SLS (L/250=8.8mm) their load carrying capacity was already attained. As Figure 4 shows, the proposed strengthening methodology is capable, not only of increasing the load at SLS, but also of providing an ultimate capacity that exceeds the load at SLS according to the Eurocode exigencies.

Table 6 presents the most relevant results of the flexural response of the tested beams, where it can be verified that, by increasing the level of the prestress force applied to the CFRP laminate, the load carrying capacity corresponding to concrete cracking and steel yielding initiation stages increase, as well as the corresponding deflection (except in the 
case of the $40 \%$ prestressed beam). At the deflection limit corresponding to the SLS requirements, the increase of the load carrying capacity with the prestress level was also quite significant. In fact, for prestress levels of $0 \%, 20 \%, 30 \%$ and $40 \%$, the increase of load carrying capacity at SLS was 32\%, 47\%, 55\% and 63\%, respectively, when compared to the control beam.

According to Figure 4, the beams prestressed with $20 \%$ and $30 \%$ exhibited similar force-deflection response in the phase between concrete cracking and steel yielding initiations due to the small difference of load at concrete cracking, and almost constant elasto-cracked stiffness of the strengthened beams. However, the cracking load was expected to increase with the prestress level, which indicates that the concrete tensile strength of the beam strengthened with $30 \%$ prestress would have been a little bit smaller than of the other beams. Similar justification can be also pointed out to the beam strengthened with a prestressed laminate at $40 \%$, although in this beam the stiffness in the elasto-cracked phase was slightly larger than the stiffness observed in the other beams, which may be justified by the smaller cracked region in consequence of the higher prestress level (as also observed by [25]), and the longitudinal reinforcements and the CFRP laminate may have been with better bond conditions, promoting a higher stiffness in the elasto-cracked stage for this beam. The rupture of the prestressed laminate in this beam, however, occurred for a smaller load, leading to a deflection smaller than the expected one. The higher flexural stiffness during the elasto-cracked stage in this beam, conjugated with the higher initial tensile strain introduced in the CFRP, may have contributed to a higher gradient of tensile stress in the flexural failure cracks, promoting the rupture of the laminate at a smaller deflection of the beam, when compared to what occurred in the other strengthened beams. The expected decrease of the deflection at failure caused by the increase of applied prestress level is visible in the beams strengthened with a laminate prestressed at $20 \%$ and $30 \%$. However, in these beams the maximum load capacity of the beam was not influenced by the applied prestress level, since they attained the same capacity of the non-prestressed beam.

Serviceability limit state (SLS) conditions should be respected by controlling the maximum crack width and deflection, as well as limiting the stress level in the longitudinal tensile steel bars, in order to ensure that this level is kept below the yield strain [26]. By increasing the prestress level in the CFRP laminates, the stress level in the longitudinal tensile steel reinforcement is decreased, as well as the crack width and crack propagation along the depth of the cross section of the beam and beam's span length, resulting in significant benefits in terms of durability due to the smaller probability of corrosion of the steel reinforcement. The results obtained in this experimental program also 
confirmed that by increasing the prestress level in the CFRP laminate, the load at steel yield initiation increases, as well as the corresponding deflection. This effect is caused by the increase of cracking load and almost constant load amplitude between crack initiation and yield initiation.

In spite of the benefits resulting from the application of prestressed CFRP laminates, Figure 4 evidences that the failure of the beams occurs for smaller deflections as the prestress level increases, which might be a concern from the point of view of ductility requirements. To analyze this issue on the tested beams, a ductility index $(\mu)$ was evaluated, assumed as capable of indicating the ability of a structural element to withstand plastic deformation without a decrease in the load carry capacity. Therefore $\mu$ is defined as the ratio between the ultimate mid-deflection $\left(u_{u}\right)$ and the deflection corresponding to the steel yield initiation $\left(u_{y}\right)$ of the beams $\left(\mu=u_{u} / u_{y}\right)$. The relationship between the normalized ductility index $\left(\mu^{\text {pre }} / \mu^{\text {pas }}\right)$ and the applied prestress level is represented in Figure 5, where $\mu^{\text {pre }}$ and $\mu^{\text {pas }}$ are the ductility indexes of the prestressed beams and passive beam, respectively. More available experimental data, including RC beams strengthened with CFRP elements prestressed at different levels reported by [15-17], were considered to evaluate the efficiency of prestress level on the normalized ductility index represented in Figure 5. This figure shows that the normalized ductility index has a tendency to decrease almost linearly with the increase of the prestress level applied to the CFRP elements up to the maximum level considered in these experimental programs. Therefore, it is suggested that for design purposes this aspect should be taken into account by limiting the level of prestress to be applied in order to do not compromise the ductility behavior of the strengthened beam. A recommendation should be also imposed for the ductility index, $u_{u} / u_{y}>\mathrm{C}$. An interval of values for the C, 1.25-1.5 seems appropriate, but further research in this topic is required.

The influence of laminate's prestress level in terms of the evolution of flexural stiffness during the loading process of the beams was also investigated. The flexural stiffness was calculated as the tangent to the load-deflection curve, and the relationship between the load and normalized flexural stiffness of the tested beams is represented in Figure 6, where normalized means that the flexural stiffness is divided by the initial uncracked flexural stiffness of the beam. Just after crack initiation, an abrupt decrease of the flexural stiffness was observed in all tested beams, and an almost equal and constant normalized flexural stiffness was determined in the cracking phase up to yield initiation. As expected, the prestress delayed the abrupt decay of the flexural stiffness due to the increase of the cracking load. The 
evolution of the normalized flexural stiffness in the post-yielding phase was similar in all the strengthened beams, as Figure 4 had already suggested.

\subsection{Internal strain distribution}

The load versus CFRP tensile strain at mid-section is depicted in Figure 7, where the initial strain corresponds to the strain after prestress release, which was already reported in Table 5. Regardless the prestress level, the CFRP laminates have behaved similarly in three phases composing a load-strain response of the tested beams. In fact, after the yielding of the tensile steel reinforcement, the increase of the load carrying capacity of the prestressed beam is practically assured by the CFRP laminate, since the contribution of the longitudinal steel bars due to its hardening effect is relatively small up to the rupture of the laminate.

In the some cases of the strengthened beams, the ultimate tensile strain of the CFRP laminate recorded by the strain gauge at mid-section (Figure 7) was higher than the ultimate strain reported in the Table 3 corresponding to the characterization of the properties of this composite. The strains recorded in the SGs installed on the laminate applied in the strengthened beams can be affected by the local curvature of the laminate, leading to higher strains compared to the situation of direct tensile tests, as reported by Barros et al. (2011) [36].

Figure 8a presents the load versus strain in the longitudinal tensile steel reinforcements at mid-span, where a strain value is the average of the values recorded in the two strain gauges installed at mid-section on the steel bars (SG 2 and 3 in Figure 1c). The prestress force has introduced an initial compressive strain on the longitudinal steel reinforcement. During the bending test, and before crack initiation, the longitudinal steel reinforcement has started presenting tensile strains. The instant of transition from compressive to tensile strain, defined as steel decompression point for the prestressed beams, is represented in Figure 8a. As expected the load corresponding to this point has tended to increase with the prestress level, and, consequently, the load at yield initiation of the longitudinal steel bars has also increased. The increase of load at the steel decompression and yield initiation, provided by the prestress level, and when the corresponding values in the non-prestressed beam are considered for comparison purposes, is depicted in Figure $8 \mathrm{~b}$. It is verified that up to a prestress level of $40 \%$ this load increase has an almost linear increase trend with the prestress level. 
The relationship between load and concrete strain at the top fiber of mid-span cross section is represented in Figure 9, where it is shown that the prestressed beams exhibited an initial small tensile strain on the concrete top fiber (less than 30 microstrain; due to deficient functioning of the strain gauge in the $40 \%$ prestressed beam, this data is not available for this beam). The prestressed beams presented a lower concrete compressive strain at failure when compared to the non-prestressed beam, which indicates that the probability of concrete crushing as prevailing failure mode is decreased by the application of prestress. This lower concrete strain at failure can be attributed to the initial strain profile introduced when releasing the prestressed laminates, causing an initial compression field in the steel bars and surrounding concrete, and a downward on the position of the neutral axis.

\subsection{Failure modes and crack patterns}

Concrete crushing is assumed to occur in RC beams when the compressive strain on the concrete top fiber of the cross section reaches its maximum usable strain $\left(\varepsilon_{\mathrm{cu}}=0.0035\right.$ according to the Eurocode [21]). In the control beam, crushing of the concrete in the compression zone after yielding of the tensile steel bars was observed, as represented in Figures 9 and 10. On the other hand, all beams strengthened with CFRP only experienced concrete crushing after CFRP rupture (see Figures 9 and 10). The adhesive provided adequate bond conditions since no debonding of the CFRP laminate from the concrete substrate was observed.

The crack pattern of all beams consisted predominantly of flexural cracks, as it can be observed in Figure 10, where the crack patterns at ultimate stage are represented. Based on these crack patterns, the average crack spacing was determined by considering all the cracks crossing the tensile steel reinforcement. A better distribution of the cracks was observed in the beams strengthened with NSM CFRP laminates, since a decrease of about $17 \%$ on the average crack spacing was noticed in the strengthened beams when compared to the average crack spacing of the control beam.

The experimental results demonstrate that the non-prestressed laminate has increased the cracked zone length in about $35 \%$ in relation to the control beam, which is justified by the increase of load carrying capacity provided by the CFRP reinforcement. However, the increase of the prestress level has decreased the cracked zone length due to the initial compressive strain field introduced by the prestress. In fact, for prestress level of $20 \%, 30 \%$ and $40 \%$, the cracked zone length was $25 \%, 8 \%$ and $11 \%$ longer than the cracked zone registered in the control beam, respectively. 


\section{Finite Element Analysis}

\subsection{FE Model description}

A 3D finite element model, including all constitutive material models of the tested beams, was used to simulate the experimental tests and to complement the analysis of this research program. Eight-node 3D solid elements were adopted to model the concrete, CFRP laminate and epoxy adhesive. 3D two-node truss elements were embedded into the concrete elements to simulate the behavior of steel reinforcements. Only one quarter of the full size beam was modeled, taking the advantage of the double symmetry of the beams, as represented in Figure 11, in order to reduce the computational time of the numerical analysis.

The loading and boundary conditions of the model were applied according to the particularities of the test setup. Preliminary analyses were carried out to obtain a mesh refinement that does not compromise the accuracy of the simulations. Furthermore, a fine mesh refinement was applied in the zones where relatively high stress gradients are expected to occur, and the final mesh is depicted in Figure11.

\subsection{Modeling of materials}

The nonlinear Concrete Damaged Plasticity (CDP) model was selected to simulate the concrete nonlinear behavior [28]. In this CDP model, the concepts of linear isotropic elasticity in combination with isotropic tensile and compressive plasticity are used to simulate the inelastic behavior of the concrete. The CDP model considers nonassociated potential plastic flow resulting in a non-symmetric stiffness matrix. The Drucker-Prager hyperbolic function was used to assess the potential flow [28].

The CDP model assumes that tensile cracking and compressive crushing of the material are the two main failure mechanisms. The concrete stress-strain relation for uniaxial compression was obtained according to the recommendations of CEB-FIP model code [27]. To describe the concrete tensile behavior, a linear stress-strain relation was assumed for uncracked concrete, and a stress-crack opening relation according to CEB-FIP model code, 
represented in Figure 12a, was used for the cracked concrete [27] (with tensile fracture energy, $\mathrm{G}_{\mathrm{f}}$, of $0.08 \mathrm{~N} / \mathrm{mm}$ recommended by [28]).

The value of the CDP model parameters were estimated based on the recommended range of values in [28-32], and adopting the following strategy:

Dilation angle, $\psi$ : is the inclination of the failure surface towards the hydrostatic axis, measured in the meridional plane. It is physically explained as the concrete internal friction angle and it usually ranges between $36^{\circ}$ and $40^{\circ}$ [32]. In the numerical simulations, the value of $38^{\circ}$ was adopted;

Plastic potential eccentricity, $e$ : adjusts the shape of meridional plane (herein assumed as a hyperbola) at which the function approaches an asymptote, meaning that the potential flow tends to a straight line in the meridional plane as the eccentricity tends to zero [28,32]. This eccentricity can be considered equal to the ratio between tensile and compressive strength of concrete, therefore the value of 0.1 was adopted, as recommended by CDP model [32];

Stress ratio $f_{b o} / f_{C 0}$ : is the ratio between the initial biaxial compressive yield stress and the initial uniaxial compressive yield stress, which was taken as 1.16 , as recommended by CDP model [28];

Shape of the loading surface, $K_{c}$ : describes the ratio of the distance between the hydrostatic axis and respectively the compression meridian and the tension meridian in the deviatoric cross section [32]. $\mathrm{K}_{\mathrm{c}}$ ranges between 0.5 and 1 , and the CDP default value of $2 / 3$ was assumed in the analyses;

Viscosity parameter, VP: it was assumed to be zero in the analyses.

Elasto-plastic models with associated plastic flow were used to simulate the behavior of epoxy adhesive and steel bars [28]. An idealized isotropic hardening plasticity model was considered to simulate the behavior of steel bars up to its ultimate tensile strength based on the simplified model recommended by CEB-FIP code (Figure 12b) [27]. On the other hand, the perfect plasticity model, with no hardening, was used to simulate the epoxy adhesive behavior, as represented in Figure 12c. A linear elastic stress-strain relation up to the ultimate tensile strength was adopted to simulate the tensile behavior of the CFRP laminates (Figure 12d). 


\subsection{Modeling of interface bond}

To simulate the bond behavior of the CFRP laminate-adhesive-concrete interfaces, two surface-based contact interfaces were defined. One was used at the laminate-epoxy adhesive interface, while the other was applied at the concrete-epoxy adhesive interface. A mixed mode of debonding including stress-separation (in the normal direction of the interface element plane) and shear stress-slip (on both directions of the interface element plane) was used to simulate the concrete-epoxy interface, while for the laminate-epoxy interface only the shear stress-slip, in both directions of the plane, was considered. A linear softening law was defined to describe damage evaluation in the interfaces.

The maximum tensile stress of the concrete-epoxy interface in the normal direction can be limited to the concrete tensile strength, resulting in the failure of the surrounding concrete when the tensile stress exceeds the concrete tensile strength $\left(f_{c t}\right)$ [33]. Accordingly, the tensile fracture energy of the concrete $\left(G_{f}\right)$ can be considered to specify the damage evaluation of the interface. So, the values of $f_{c t}=2.51 \mathrm{MPa}$ and $G_{f}=0.08 \mathrm{~N} / \mathrm{mm}$ were used for modeling the normal stress-separation behavior.

To simulate both directions of the shear stress-slip interface between the epoxy adhesive and the concrete, interface properties, including the maximum shear stress $\left(\tau_{\max }\right)$ and shear fracture energy $\left(G_{f s}\right)$, were obtained from Eqs.(1-3), recommended by [34].

$$
\begin{gathered}
\tau_{\text {max }}=(0.802+0.078 \cdot \varphi) \cdot f_{c m}^{0.6} \\
\delta_{\text {max }}=\left(0.976 \cdot \varphi^{0.526}\right) /(0.802+0.078 \cdot \varphi) \\
G_{f s}=\left(\tau_{\max } . \delta_{\text {max }}\right) / 2
\end{gathered}
$$

where $\varphi$ is the aspect ratio of the interface failure plane, defined as (groove depth $\left.+t_{d}\right) /\left(\right.$ groove width $\left.+2 . t_{b}\right)$ with $t_{d}=$ $t_{b}=1 \mathrm{~mm}, \delta_{\max }$ is maximum shear slip, and $f_{c m}$ is the concrete average compressive strength. According to these equations and the geometric/material characteristics of the beams previously described, the values of $\tau_{\max }=8.4 \mathrm{MPa}$, and $G_{f s}=7.1 \mathrm{~N} / \mathrm{mm}$ were used for the shear stress-slip model. 
Analysis were carried out to assess the influence of the aspect ratio of the interface failure plane on the flexural response of the prestressed beams, by considering $t_{d}=t_{b}=0,3$, and $5 \mathrm{~mm}$. It was observed that the effect of this parameter on the flexural response of the prestressed beams is negligible.

The following shear stress-slip law, recommended by [35], was adopted to simulate the behavior of shear-slip interface in both directions between the epoxy adhesive and the CFRP laminate:

$$
\tau(s)= \begin{cases}\tau_{m}\left(\frac{s}{s_{m}}\right)^{\alpha} & s \leq s_{m} \\ \tau_{m}\left(\frac{s}{s_{m}}\right)^{-\alpha^{\prime}} & s>s_{m}\end{cases}
$$

where $\tau_{m}$ and $s_{m}$ are the maximum shear stress and its corresponding slip, respectively, and $\alpha$ and $\alpha^{\prime}$ are parameters defining the shape of the pre- and post-peak $\tau$-s curves. The values of these parameters were found in literature [35] for concrete with similar strength to the one of the tested beams. The shear fracture energy $\left(G_{f s}\right)$ of this interface was estimated to be equal to the area under the shear stress-slip curve. Thus, the values of $\alpha=0.16, \alpha=0.32, s_{m}=0.23 \mathrm{~mm}$, $\tau_{m}=20 \mathrm{MPa}$ and $G_{f s}=23.56 \mathrm{~N} / \mathrm{mm}$ were used for defining the shear bond-slip model.

These equations were selected due to their simplicity and ability to simulate appropriately the bond behavior between epoxy adhesive and both CFRP laminate and concrete.

\subsection{Assessment of the predictive performance of the numerical strategy}

To reproduce, as much as possible, the real test conditions for the prestressed beams, four steps of analysis were numerically adopted to simulate the experimental prestress procedure.

Step 1: Applying prestressing force on the CFRP laminate;

Step 2: Introducing the interfaces between concrete/epoxy adhesive and CFRP laminate/epoxy adhesive, assuming that the properties of the interfaces correspond to a hardened stage of the epoxy;

Step 3: $\quad$ Release the prestressing force; 
Step 4: Applying the monotonic load up to the collapse of the beam.

To assess the performance of the described numerical model, this strategy was applied to simulate the tests of the beams, and the obtained load versus mid-deflection response is compared in Figure 13 with the ones registered experimentally.

Numerical prediction of the prevailing failure modes at the maximum capacity of the beams was same as the experimental results, but some deviation was obtained on the prediction of the deflection at maximum load. It worth to note that the smaller predictive performance on the numerical simulation of the $40 \%$ prestressed beam can be related to the unexpected behavior of this beam, as explained in section 3-2.

The numerical model has also confirmed that by increasing the prestress level in the laminate, the failure of the strengthened beams occurs at smaller deflection. The relationship between the applied prestress level and the normalized ductility index to the passive beam, obtained experimentally and numerically, is compared in Figure 14a, where, a part the beam prestressed at $40 \%$, a very good prediction is shown. A good predictive performance in terms of tensile strains recorded in the laminate and steel reinforcement, as well as, compressive strain monitored at the concrete top surface of mid-span cross section, is also evidenced in Figure 14b, 14c, and 14d, respectively, where the corresponding values for the non-prestressed beam in comparison with the either or both of $20 \%$ and $30 \%$ prestressed beams are considered in order to obtain a better representation of the figures.

\section{Conclusion}

This work has explored the use of prestressed carbon-fiber-reinforced-polymer (CFRP) laminates, applied according to the near-surface-mounted (NSM) technique, for the flexural strengthening of reinforced concrete (RC) beams. The influence of the prestress level applied on the CFRP laminate was assessed by performing an experimental program composed of five beams. A 3D nonlinear finite element model was also developed to simulate the flexural behavior of the tested beams. From the obtained results the following main remarks can be pointed out.

- After releasing the prestress force, a negative camber is generated due to the negative bending moment caused by the eccentricity of this force in relation to the centroidal axis of the beam's cross section. This negative camber resulted 
in a decrease of tensile strain in the prestressed CFRP laminate, which represents the short-term prestress loss immediately after release.

- The prestress force created an initial compressive strain in the tensile steel reinforcement and surrounding concrete, which led to an increase of the load carrying capacity at concrete cracking and steel yielding initiations.

- Based on the results obtained for the control beam, all CFRP strengthened beams provided an increase in terms of ultimate load carrying capacity, regardless the prestress level applied to the CFRP laminate.

- The load carrying capacity at serviceability limit conditions increased significantly with the prestress level, when compared to the load carrying capacity of the beam strengthened with a non-prestressed CFRP laminate. However, the ultimate deflection of the strengthened beams decreased with the increase of applied prestress level. These results, which imply a decrease of the ductility index with the prestress level, suggest the adoption of an upper limit of the prestress level to be applied to the CFRP laminates in order do not compromise the ductility performance of the RC beams strengthened according to the proposed technique.

- All strengthened beams failed by rupture of the CFRP laminate after the yielding of the tension steel reinforcement. The results showed that the possibility of the concrete crushing as the prevailing failure mode decreases with the increase of the prestress level applied to the CFRP laminate.

- The crack patterns of all beams consisted predominantly of flexural cracks. The cracked zone length of the beam strengthened with a non-prestressed NSM CFRP laminate increased when compared to the control beam, while the increase of the prestress level inverted this tendency, by decreasing the cracked zone length in comparison to the passive strengthened beam. The strengthening system, regardless the prestress level, has also provided a decrease of average crack spacing when compared to the control beam.

- A 3D nonlinear FE approach simulating both concrete/adhesive and laminate/adhesive interfaces, as well as, the relevant nonlinear behavior of the intervening materials, was proposed, and its good predictive performance was demonstrated. This modelling strategy can be used to design the type of structures investigated in the present work.

\section{Acknowledgments}


The study reported in this paper is part of the project "PreLami - Performance of reinforced concrete structures strengthened in flexural with an innovative system using prestressed NSM CFRP laminates", with the reference PTDC/ECM/114945/2009. The first author acknowledges the grant provided by this project, and second author also wishes to acknowledge the scholarship granted by FCT (SFRH/BD/61756/2009). The authors would also like to acknowledge the support provided by CLEVER Reinforcement Iberica Company, for supplying the adhesives and the laminates, and Casais and CiviTest for the preparation of the beams.

\section{Reference}

1. ACI 440.2R. Guide for the Design and Construction of Externally Bonded FRP Systems for Strengthening Concrete Structures, American Concrete Institute, 2008.

2. Barros J, Fortes A. Flexural Strengthening of Concrete Beams with CFRP Laminates Bonded into Slits. Journal Cement and Concrete Composites, 2005, 27(4) p: p. 471-480.

3. Nanni A. North American Design Guidelines for Concrete Reinforcement and Strengthening using FRP: Principles, Applications and Unresolved Issues, Construction and Building Materials, 2003, 17: p. 439-446.

4. Dias S, Barros J. Shear Strengthening of RC Beams with NSM CFRP Laminates: Experimental Research and Analytical Formulation. Composite Structures, 2012, 99: p. 477-490.

5. Hong K, Han J, Seo D, Han S. Flexural response of reinforced concrete members strengthened with nearsurfaced-mounted CFRP strips. International Journal of Physical Sciences, 2011, 6(5), pp. 948-961.

6. Zhang H, Wang L, Liu G. Flexural behavior and ductility of concrete beams strengthened with nearsurface mounted GFRP bars. Advanced Materials Research, 2011, 163-167, pp. 3610-3614.

7. Barros J, Varma R, Sena-Cruz J, Azevedo A. Near Surface Mounted CFRP Strips for the Flexural Strengthening of RC Columns - Experimental and Numerical Study. Engineering Structures Journal, 2008, 30(12): p. 3412-3425.

8. Yost J, Gross S, Dinehart D, Mildenberg J. Flexural behavior of concrete beams strengthened with nearsurface-mounted CFRP strips. ACI Structural Journal, 2007, 104(4), pp. 430-437.

9. El-Hacha R, S. Riskalla. Near-Surface-Mounted Fiber-Reinforced Polymer Reinforcements for Flexural Strengthening of Concrete Structures. ACI Structural Journal, 2004, 101(5): p. 717-726. 
10. Barros J, Dias S, Lima J. Efficacy of CFRP-based Techniques for the Flexural and Shear Strengthening of Concrete Beams. Journal Cement and Concrete Composites, 2007, 29(3).

11. Breveglieri M Barros J, Dalfré G, Aprile A. A Parametric Study About the Effectiveness of the NSM Technique for the Flexural Strengthening of Continuous RC Slabs. Composites Part B: Engineering, 2012, 43, 1970-1987.

12. Perrone M, Barros J, Aprile A. A CFRP-Based Strengthening Technique to Increase the Flexural and Energy Dissipation Capacities of RC Columns, Journal of Composites for Construction, ASCE, 2009, 13 (5), 372 383.

13. Soliman S, El-Salakawy E, Benmokrane B. Flexural behaviour of concrete beams strengthened with near surface mounted fibre reinforced polymer bars. Canadian Journal of Civil Engineering, 2010, 37(10), pp. 1371-1382.

14. Nordin H, Taljsten B. Concrete Beams Strengthened with Prestressed Near Surface Mounted CFRP. Journal of Composites for Construction, 2006, 10(1): p. 60-68.

15. El-Hacha R, Gaafar M. Flexural Strengthening od Reinforced Concrete Beams Using Prestressed NearSurface-Mounted CFRP Bars. Precast/Prestressed Concrete Institue, c/o PCI Journal, 200W, Fall 2011.

16. Badawi M, Soudki K. Flexural Strengthening of RC Beams with Prestressed NSM CFRP Rods-Experimental and Analytical Investigation. Journal of Construction and Building Materials, 2009, p. 3292-3300.

17. Hajihashemi A, Mostofinejad D, Azhari M. Investigation of RC Beams Strengthened with Prestressed NSM CFRP Laminates. Journal of Composites for Construction (ASCE), 2011, 15(6).

18. Barros J. NSM Post-tensioned CFRP Laminates for the Flexural Strengthening of RC Beams. in 9th International Symposium on Fiber Reinforced Polymer Reinforcement for Concrete Structures (FRPRCS-9): 2009, Sydney, Australia.

19. Rezazadeh M, Costa I, Barros J. Assessment of the Effectiveness of Prestressed NSM CFRP Laminates for the Flexural Strengthening of RC Beams. in 11th International Symposium on Fiber Reinforced Polymer Reinforcement for Concrete Structures (FRPRCS11), 2013, Guimaraes, Portugal.

20. Ding Y, Zhang M, Zhang C. Concrete beams strengthened with prestressed near surface mounted helical rib steel wire, Advanced Materials Research, 2011, 255-260, pp. 99-104.

21. EN 1992-1-1. Design of Concrete Structures. Part 1-1: General Rules and Rules for Buildings. 2004. 
22. Costa I, Barros J. Design and Development of Hydraulic-Electro-Mechanical System to Apply Pre-Stressed CFRP Laminates According to the NSM Technique in Laboratory Conditions. Technical Report No: 12DEC/E-10, March 2012, University of Minho, 59 pp.

23. Barros J. Pre-Stress Technique for the Flexural Strengthening with NSM-CFRP Strips. in 9th International Symposium on Fiber Reinforced Polymer Reinforcement for Concrete Structures: 2009, Sydney, Australia.

24. Costa I, Barros J. Design of a system to apply prestressed CFRP laminates according to the NSM technique for the flexural strengthening of RC elements. Technical Report No: 09DEC/E-29, December 2009, University of Minho, (in Portuguese).

25. Hosseini M, Dias S, Barros J. Effectiveness of prestressed NSM CFRP laminates for the strengthening of RC slabs. Composite Structures Journal, 2013, 111, pp:249-258.

26. ACI 440.1R-06. Guide for the Design and Construction of Structural Concrete Reinforced with FRP Bars. American Concrete Institute 440, Editor 2006.

27. CEB-FIP model code 2010, Final draft 2011.

28. ABAQUS: Abaqus analysis user's manual, Version 6.11, 2011, Dassault Systemes.

29. Jankowiak T, Lodigowski T. Identification of Parameters of Concrete Damage Plasticity Constitutive Model. Foundation of civil and environmental engineering, 2005, No. 6.

30. Malm R. Predicting Shear Type Crack Initiation and Growth in Concrete with Non-linear Finite Element Method. Royal Institute of Technology (KTH), 2009, Stockholm, Sweden.

31. Lorence W, Ignatowicz R, Kubica E. Numerical Model of Shear Connection by Concrete Dowels. Structural Engineering, Mechanics and Computation 3.

32. Kmiecik P, Kaminski, M. Modeling of Reinforced Concrete Structures and Composite Structures with Concrete Strength Degradation Taken into Consideration. Archives of civil and mechanical engineering, Wroclaw University of Technology, 2011, No.3, Poland.

33. Omran H, El-Hacha R. Nonlinear 3D FE Modeling of RC beams Strengthened with Prestressed NSM-CFRP strips. Journal of Construction and Building Materials, 2011, pp: 74-85.

34. Seracino R, Saifulnaz M, Oehlers D. Generic Debonding Resistance of EB and NSM Plate-to-Concrete Joints. Journal of Composites for construction (ASCE), 2007, Vol.11, No.1. 
35. Cruz S, Barros J. Modeling of Bond between Near Surface Mounted CFRP Laminate Strips and Concrete. Journal of Computers and Structures, 2004, pp:1513-1521.

36. Barros J, Costa I, Ventura-Gouveia A, CFRP flexural and shear strengthening technique for RC beams: experimental and numerical research. Advances in Structural Engineering Journal, 2011, 14(3), pp:559-581. 

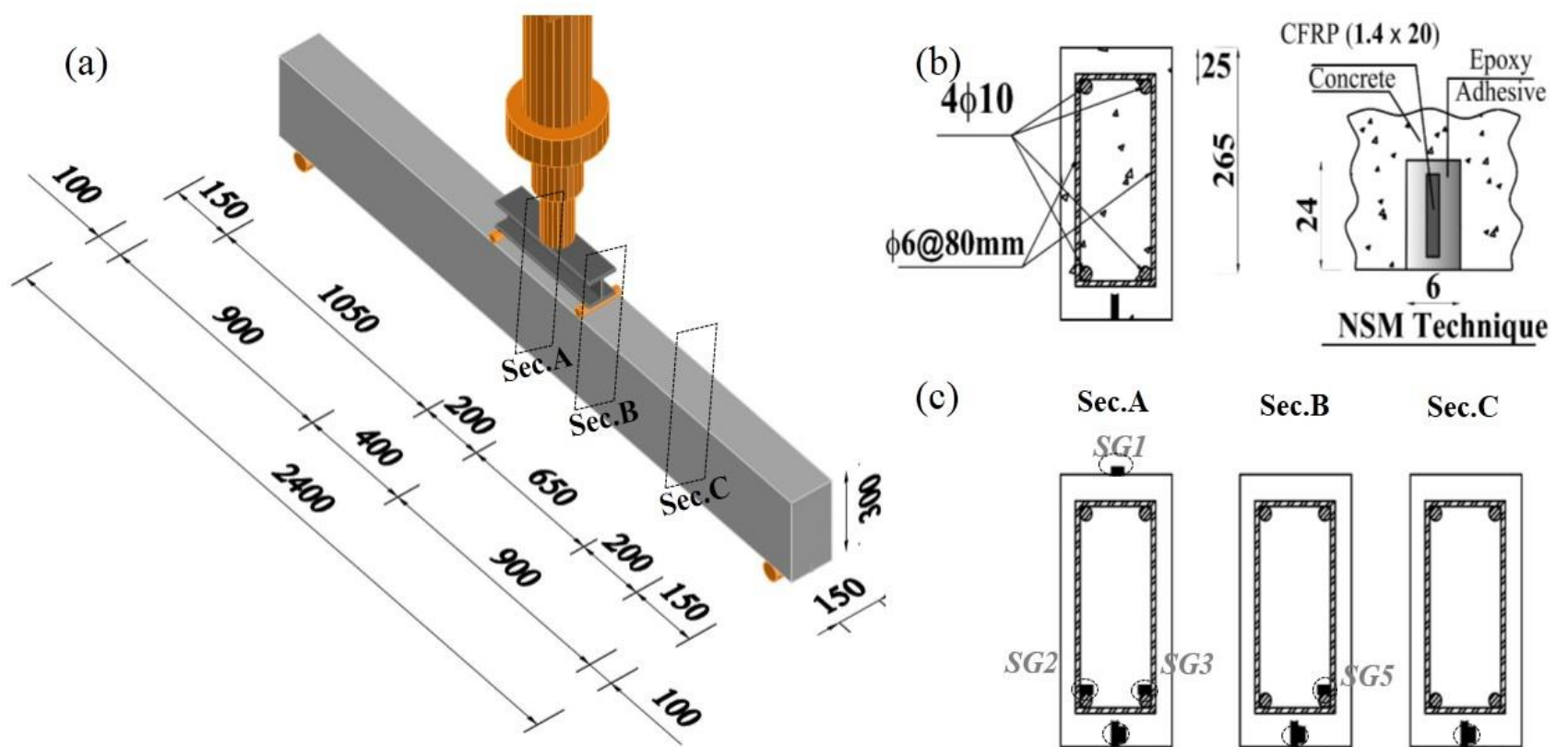

(c)

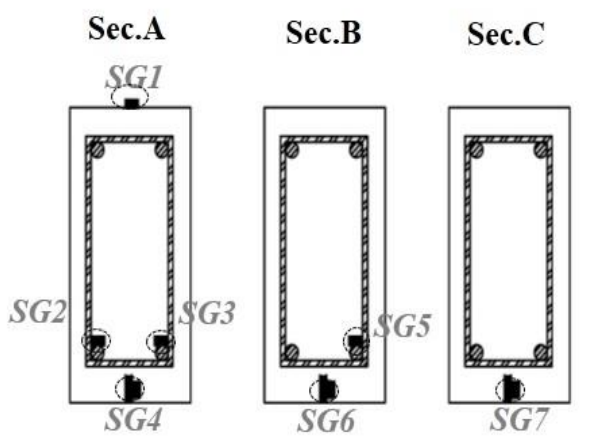

Figure 1: Characteristics of the tested type of beams: a) geometry, support and loading conditions, b) steel and CFRP reinforcements, c) positioning of the strain gauges (dimensions in $\mathrm{mm}$ ) 


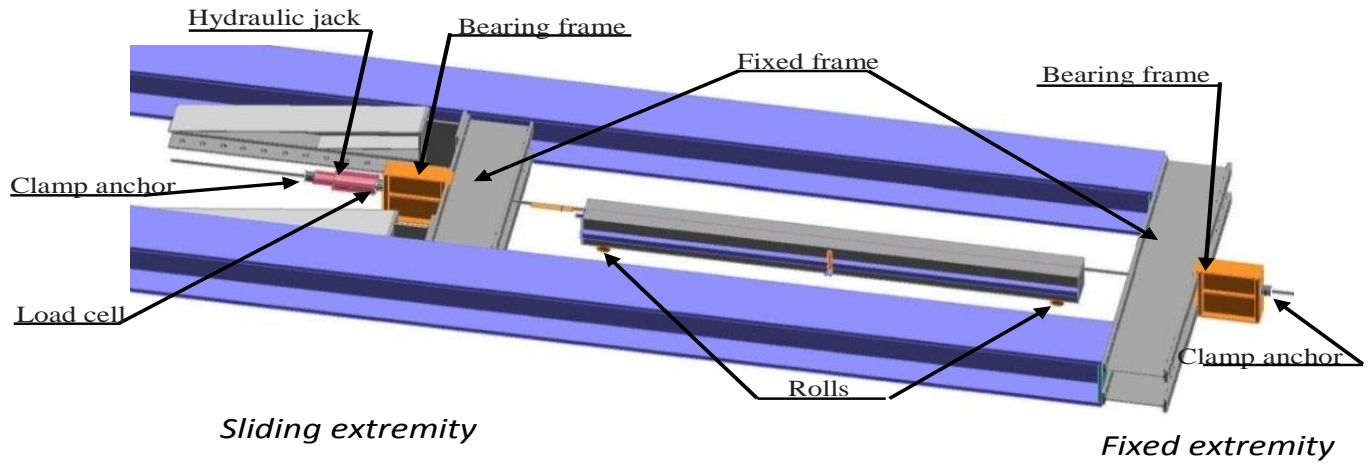

Figure 2: Prestressing system 


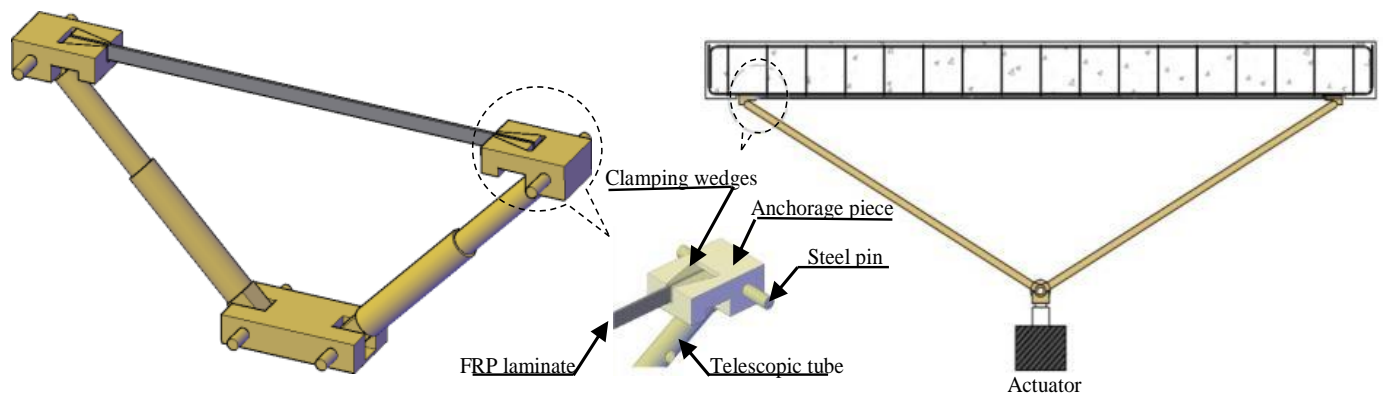

Figure 3: Prestressing system for real applications developed by Barros [23] 


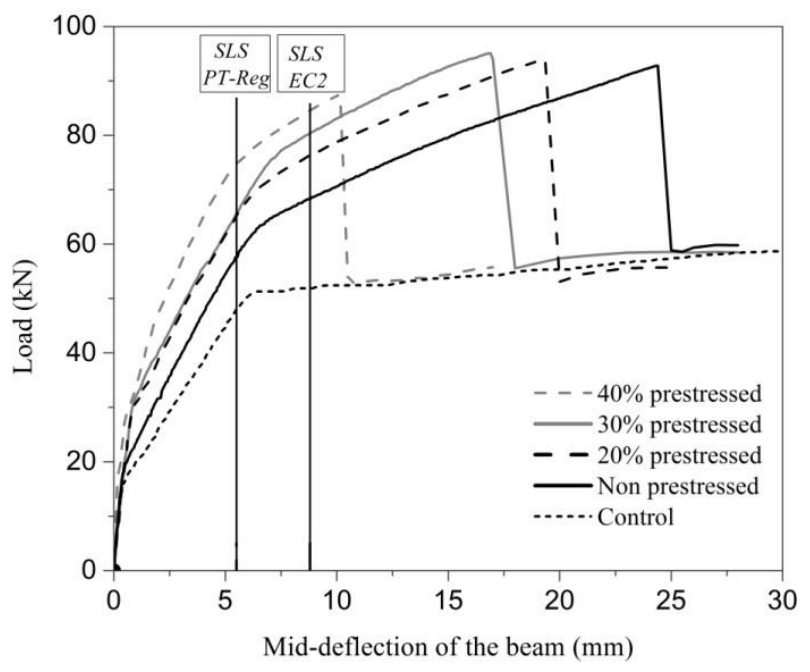

Figure 4: Load versus mid-span deflection of the tested beams 


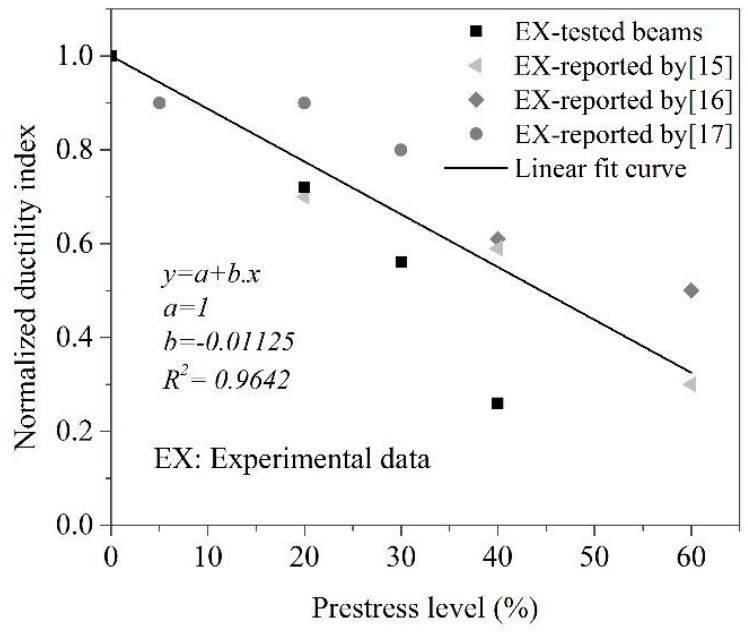

Figure 5: Ductility index of the prestressed beams normalized to passive strengthened beam 


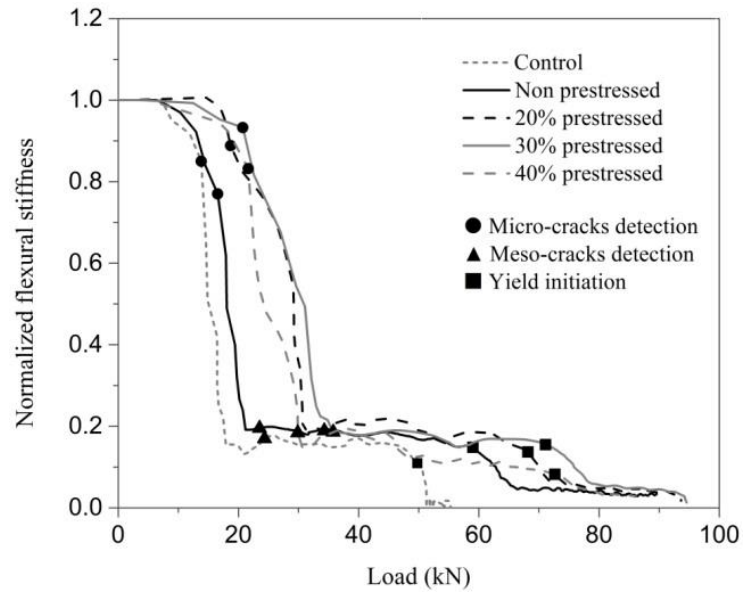

Figure 6: Load versus normalized flexural stiffness of the beams 


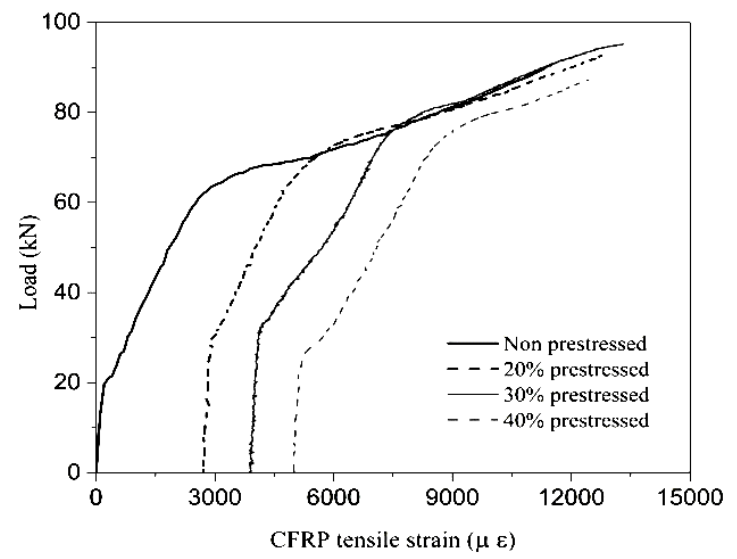

Figure 7: Load versus tensile strain in the CFRP laminate 


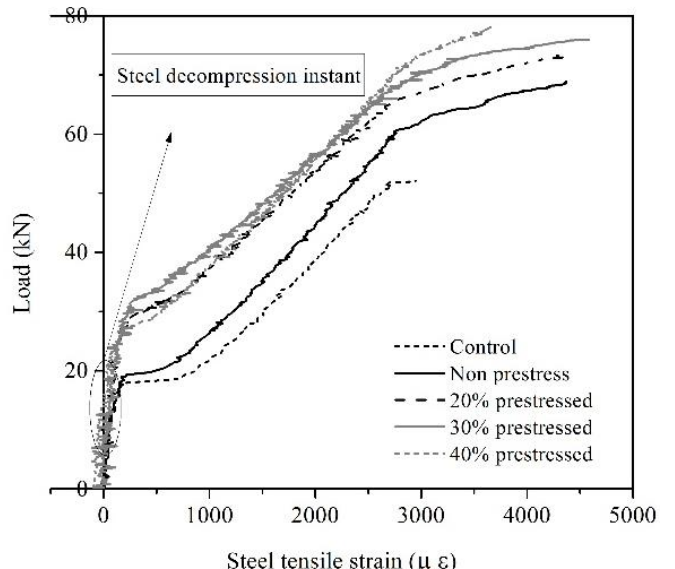

a)

Figure 8: a) Load versus strain in the tensile steel reinforcement, b) prestress level versus load increase at steel decompression and at steel yield initiation by considering the corresponding values of the non-prestressed strengthened beam

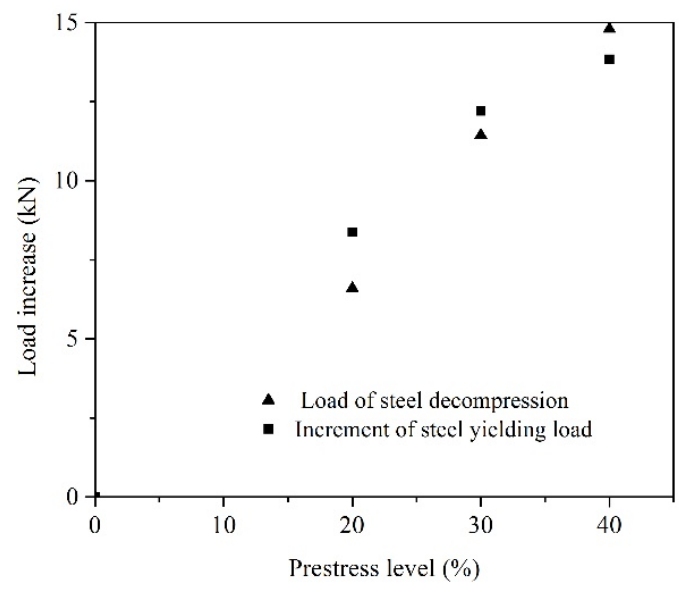

b) 


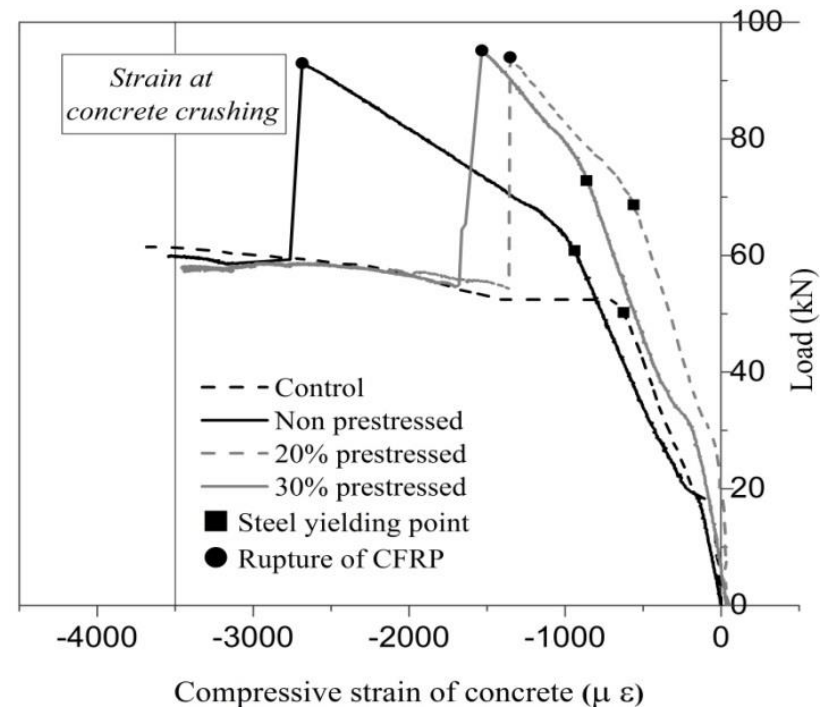

Figure 9: Load-concrete strain of the tested RC beams 


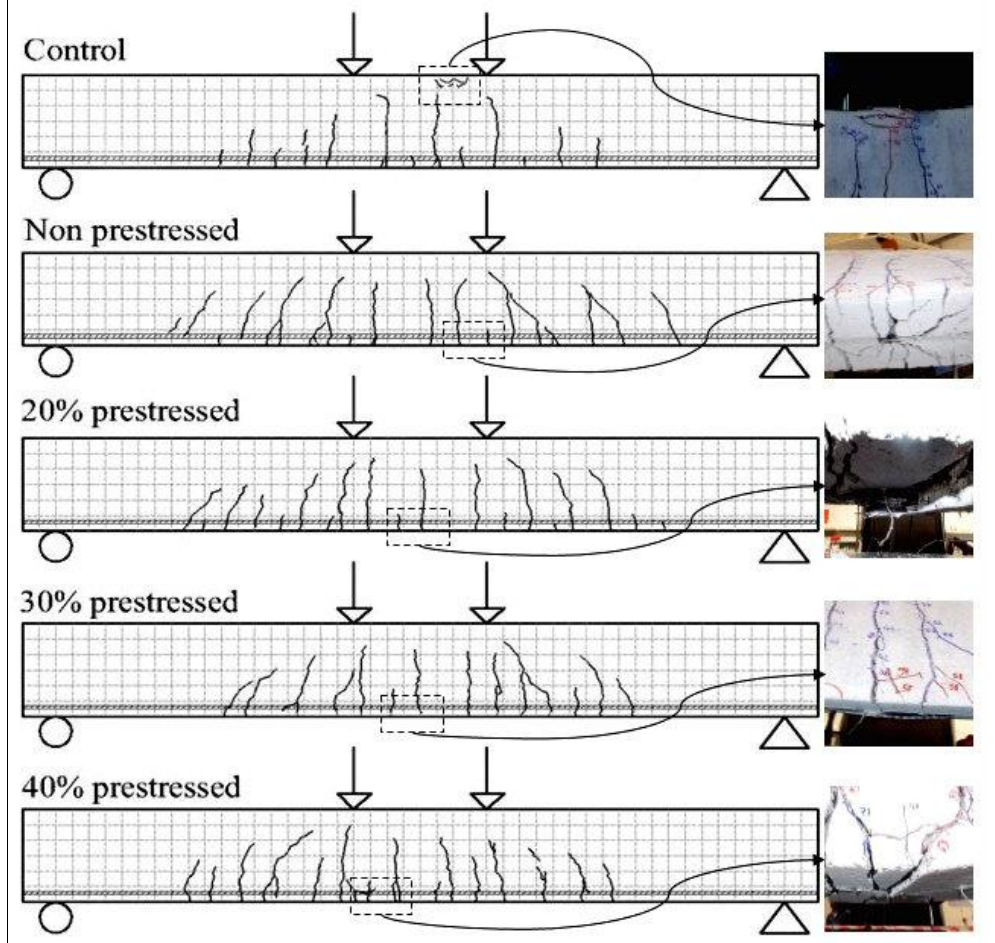

Figure 10: Crack pattern at the ultimate stage of the tested beams 


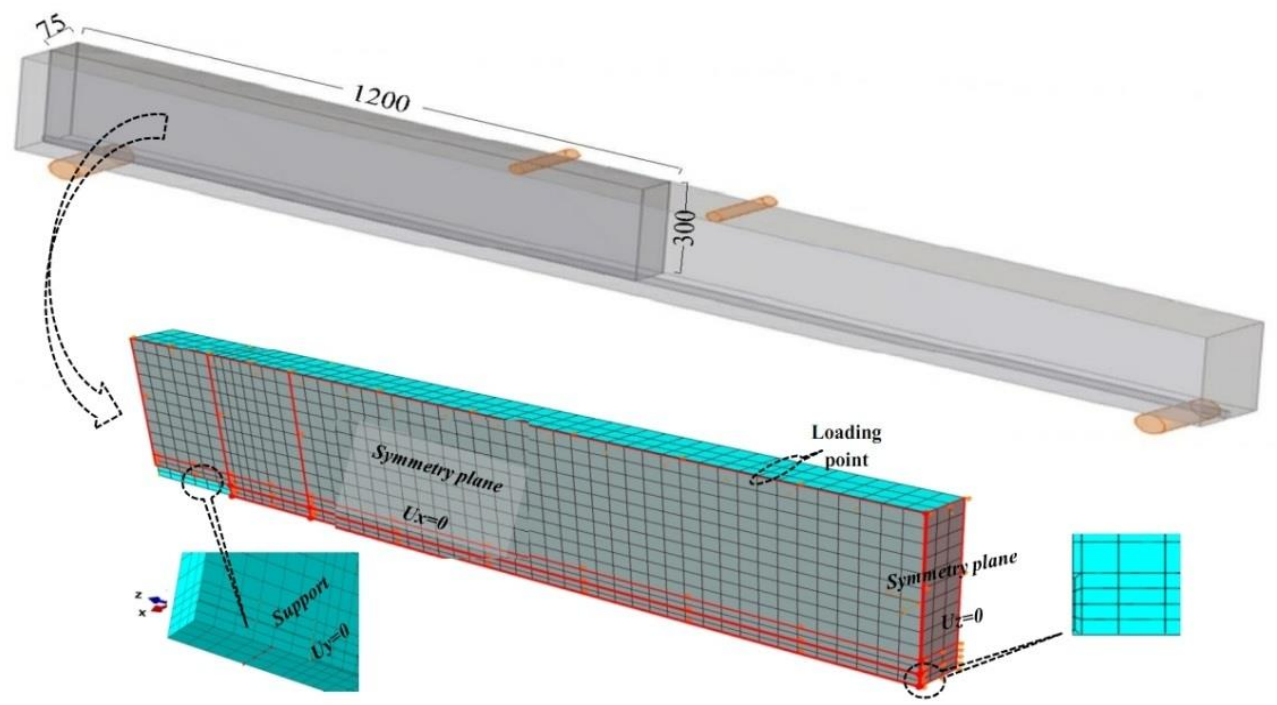

Figure 11: Boundary condition and meshing of the FE model 

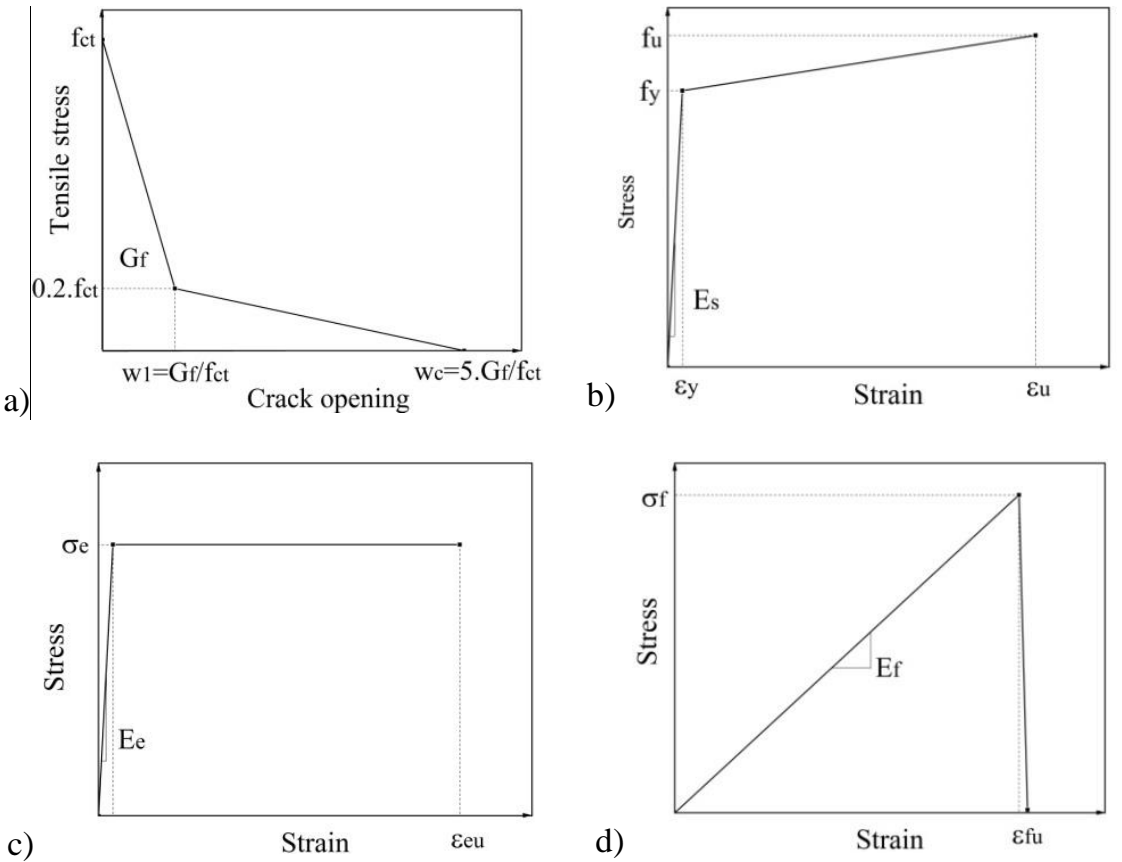

Figure 12: Modeling of constitutive materials including: a) concrete, b) steel bars, c) epoxy adhesive, d) CFRP laminate. 

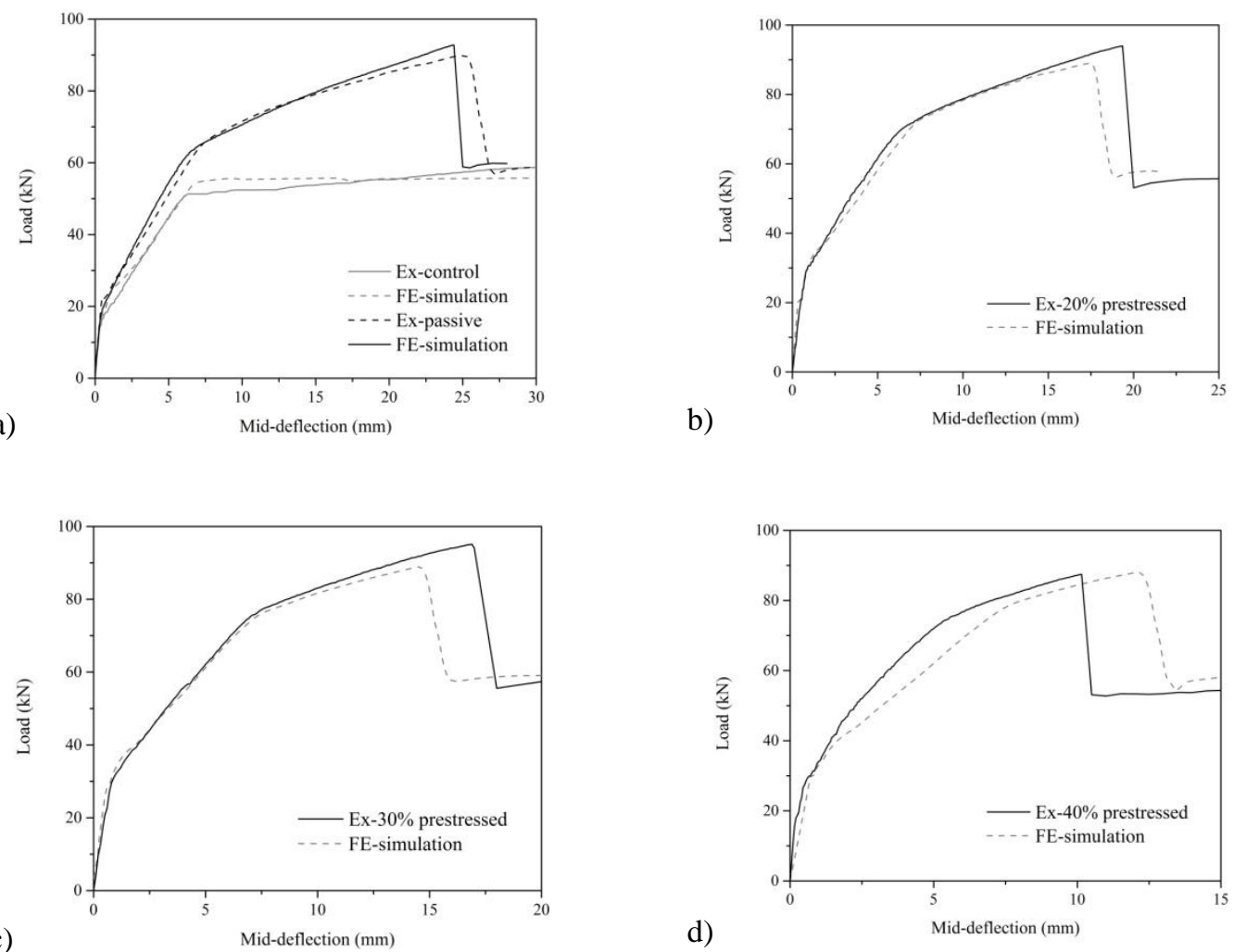

Figure 13: Numerical simulation of the experimental results: a) control and passive beams, b) 20\%prestressed beam, c) $30 \%$ prestressed beam, d) $40 \%$ prestressed beam. 


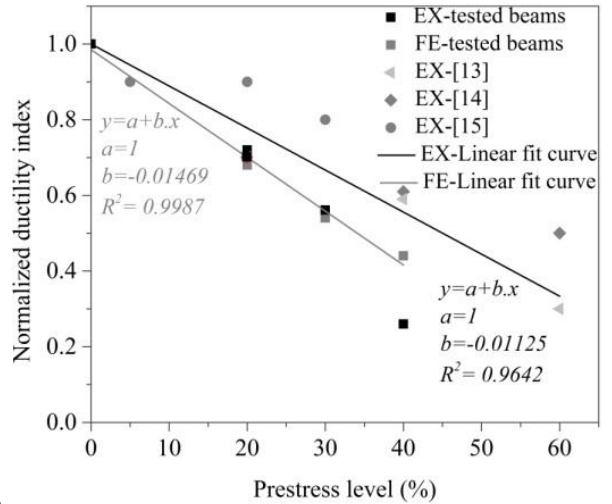

a)

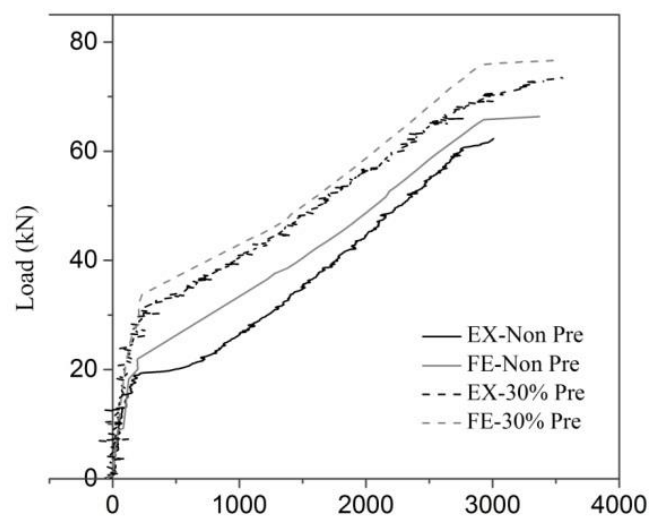

c)

Steel tensile strain $(\mu \varepsilon)$
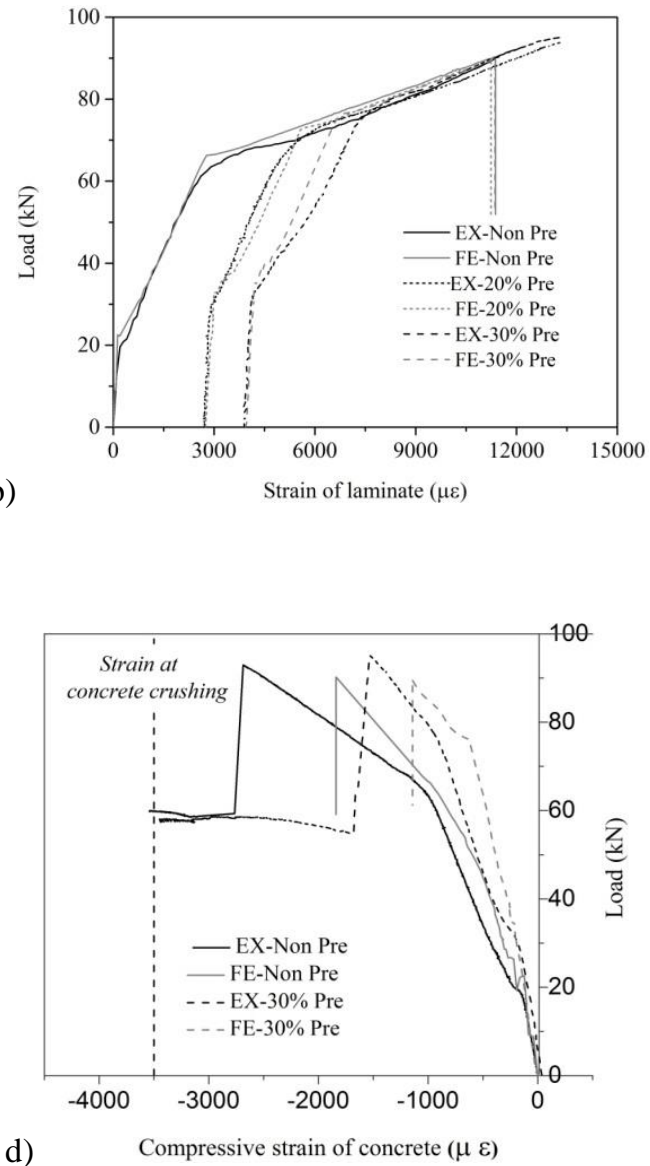

Figure 14: Numerical simulation: a) normalized ductility index to the passive beam, b) strain of CFRP laminate at mid-span, c) strain of tensile steel reinforcement at mid-span, d) strain at top fiber of concrete at mid-span 
Table 1: Concrete properties

\begin{tabular}{ccc}
\hline \multirow{2}{*}{ Age } & \multicolumn{2}{c}{ Properties } \\
\cline { 2 - 3 } & $f_{c m}(\mathrm{MPa})$ & $E_{c}(\mathrm{MPa})$ \\
\hline At 28 days & $21.2(3.3)$ & $25.9 \times 10^{3}\left(2.0 \times 10^{3}\right)$ \\
\hline At 153 days* & $32.2(1.1)$ & $27.4 \times 10^{3}\left(2.4 \times 10^{3}\right)$ \\
\hline * Beam testing age & \\
(value) Standard deviation &
\end{tabular}


Table 2: Steel bars properties

\begin{tabular}{cccc}
\hline \multirow{2}{*}{ Steel bars } & \multicolumn{3}{c}{ Properties } \\
\cline { 2 - 4 } & $f_{\text {sym }}(\mathrm{MPa})$ & $f_{\text {sum }}(\mathrm{MPa})$ & $E_{s}(\mathrm{MPa})$ \\
\hline$\varnothing 6$ & $613(14)$ & $696(9)$ & $218 \times 10^{3}\left(8 \times 10^{3}\right)$ \\
\hline$\varnothing 10$ & $585(3)$ & $656(4)$ & $208 \times 10^{3}\left(6 \times 10^{3}\right)$ \\
\hline
\end{tabular}

(value) Standard deviation 
Table 3: CFRP laminate properties

\begin{tabular}{cccc}
\hline \multirow{2}{*}{ CFRP laminate } & \multicolumn{3}{c}{ Properties } \\
\cline { 2 - 4 } & $f_{\text {fum }}(\mathrm{MPa})$ & $E_{f}(\mathrm{MPa})$ & $\varepsilon_{\text {um }}(\%)$ \\
\hline$L 20 \times 1.4$ & $1922(47)$ & $164 \times 10^{3}\left(7 \times 10^{3}\right)$ & $11.7(0.4)$ \\
\hline
\end{tabular}

(value) Standard deviation 
Table 4: Epoxy adhesive properties

\begin{tabular}{lcc}
\hline \multirow{2}{*}{ Sample } & \multicolumn{2}{c}{ Properties } \\
\cline { 2 - 3 } & $f_{\text {eum }}(\mathrm{MPa})$ & $E_{e}(\mathrm{MPa})$ \\
\hline Epoxy adhesive & $20(1.4)$ & $7 \times 10^{3}\left(0.2 \times 10^{3}\right)$ \\
\hline (value) Standard deviation
\end{tabular}


Table 5: Main results after prestress releasing

\begin{tabular}{ccccc}
\hline Beam with prestress level & $\begin{array}{c}\text { Strain before prestress } \\
\text { releasing } \\
(\mu \varepsilon)\end{array}$ & $\begin{array}{c}\text { Strain after prestress } \\
\text { releasing } \\
(\mu \varepsilon)\end{array}$ & $\begin{array}{c}\text { Prestress } \\
\text { losses } \\
(\%)\end{array}$ & $\begin{array}{c}\text { Negative camber at } \\
\text { mid-section } \\
(\mathrm{mm})\end{array}$ \\
\hline $20 \%$ & 2626 & 2616 & 0.4 & 0.08 \\
\hline $30 \%$ & 4115 & 4062 & 1.3 & 0.18 \\
\hline $40 \%$ & 5117 & 5020 & 1.9 & $*$ \\
\hline
\end{tabular}

*Data was missed due to deficient functioning of the sensor 
Table 6: Relevant results obtained in the tested beams

\begin{tabular}{|c|c|c|c|c|c|c|c|c|}
\hline RC beams & $\begin{array}{l}P c r \\
(k N)\end{array}$ & $\begin{array}{l}\Delta c r \\
(m m)\end{array}$ & $\begin{array}{c}P y \\
(k N)\end{array}$ & $\begin{array}{c}\Delta y \\
(m m)\end{array}$ & $\begin{array}{c}P u \\
(k N)\end{array}$ & $\begin{array}{c}\Delta u \\
(m m)\end{array}$ & $\begin{array}{l}P s r \\
(k N)\end{array}$ & $\frac{P_{s r}-P_{s r c}}{P_{s r c}}(\%)$ \\
\hline Control & 13.81 & 0.30 & 49.7 & 5.87 & 61.46 & 45.7 & 51.86 & 0.00 \\
\hline Non prestressed & 17.01 & 0.35 & 60.32 & 5.93 & 92.97 & 24.46 & 68.32 & 31.74 \\
\hline $20 \%$ prestressed & 22.14 & 0.46 & 68.69 & 6.14 & 94.00 & 19.36 & 76.38 & 47.28 \\
\hline $30 \%$ prestressed & 23.04 & 0.55 & 72.52 & 6.52 & 95.16 & 16.92 & 80.35 & 54.94 \\
\hline $40 \%$ prestressed & 25.08 & 0.47 & 74.16 & 5.34 & 87.45 & 10.15 & 84.56 & 63.05 \\
\hline $\begin{array}{ll}\text { - } & P_{c r} \text { is th } \\
\text { - } & P_{y} \text { is th } \\
\text { - } & P_{u} \text { is th } \\
\text { - } & P_{s r} \text { is th } \\
\text { - } & P_{s r c} \text { is t }\end{array}$ & $\begin{array}{l}\text { ad at } \\
d \text { at } y \\
\text { imate } \\
\text { ad at } \\
\text { ad at }\end{array}$ & $\begin{array}{l}\text { king i } \\
\text { initia } \\
\text { and }\end{array}$ & $\begin{array}{l}\text { tion } \\
\text { of th } \\
\text { s col }\end{array}$ & $\begin{array}{l}\Delta_{c r} \text { it } \\
\text { ngitu } \\
\text { ondir }\end{array}$ & $\begin{array}{l}\text { resp } \\
1 \text { ten } \\
\text { eflec }\end{array}$ & $\begin{array}{l}\mathrm{g} \mathrm{de} \\
\operatorname{ars~a}\end{array}$ & $\begin{array}{l}\text { on; } \\
\text { its c }\end{array}$ & nding deflection \\
\hline
\end{tabular}

